\title{
Qua licet et sequitur pudor est miscendus amori (Ov.epist.4.9): la transgresión de los límites y los límites de la transgresión en la carta de Fedra*
}

\author{
Rosario CORTÉs TOVAR \\ Universidad de Salamanca \\ rocor@usal.es
}

Recibido: 11 de diciembre de 2012

Aceptado: 21 de diciembre de 2012

\section{RESUMEN}

La epístola de Fedra a Hipólito se singulariza habitualmente dentro de las Heroides, entre otras razones, por ser una carta de seducción; pero, si bien al principio lo es, luego la voz de Fedra va cambiando hasta convertirse en discurso de persuasión abierta y en su último tramo en súplica. Para elaborar las palabras que pone en boca de la heroína cretense, Ovidio se ha inspirado en las que Eurípides le prestó antes en sus tragedias, pero en la transposición elegíaca de la heroína trágica, se ha servido, sobre todo, de su propia voz de poeta elegíaco, que determina las actitudes masculinas de Fedra en posición de poder con respecto a su joven destinatario, pero también de la voz femenina de Sulpicia y de la que le presta a esta el amicus Sulpiciae. En el estudio de todas estas alternancias y combinaciones de voces destacamos la transgresión de los límites de 'género' y las limitaciones a la misma.

Palabras clave: Epístola. Elegía. Género. Voces femeninas y masculinas.

CORTÉs Tovar, R., «Qua licet et sequitur pudor est miscendus amori (Ov.epist.4.9): la transgresión de los límites y los límites de la transgresión en la carta de Fedra», Cuad. Fil. Clás. Estud. Lat. 32.2 (2012) 247-269.

Qua licet et sequitur pudor est miscendus amori (Ov.epist.4.9): the Transgression of Limits and the Limits of Transgression on Phaedra's Letter

\begin{abstract}
Phaedra's epistle to Hippolytus generally stands out in the Heroides, among other reasons for being a letter of seduction. However, even though it is one at the beginning, later on Phaedra's voice gradually changes until it becomes a discourse of open persuasion and finally, a supplication. To devise the words he attributes to the Cretan heroine, Ovid took his inspiration from those Euripides gave her earlier on in his tragedies, but in the elegiac transposition of the tragic heroine, he employed, above all, his own voice as elegiac poet, which determines Phaedra's masculine attitudes in a position of power with respect to her young addressee. Nevertheless, the feminine voice of Sulpicia and that which the amicus Sulpiciae lends her are also employed. In the study of these combinations of voices we point up the transgression of limits of gender and and their limitations.
\end{abstract}

Keywords: Epistle. Elegy. Gender. Female and manly voices.

* Este artículo ha sido realizado en el marco del proyecto FFI2009-09531. 
CORTÉs TOVAR, R., «Qua licet et sequitur pudor est miscendus amori (Ov.epist.4.9): the Transgression of Limits and the Limits of Transgression on Phaedra's Letter», Cuad. Fil. Clás. Estud. Lat. 32.2 (2012) 247-269.

La singularidad de esta carta en el marco de la colección ovidiana ha sido señalada prácticamente por todos los estudiosos que se han ocupado de ella y de Heroides en general. A diferencia de la mayoría de las heroínas, que intentan hacer volver al héroe ausente o pérfido, de cuyo descuido o traición han sido víctimas, Fedra lo que pretende es conquistar a su hijastro Hipólito: no se trata de recuperar un amor perdido, sino de iniciar una relación prohibida.

Las aportaciones más recientes a su estudio parten de las perspectivas metodológicas que se han ido imponiendo en el estudio de las Heroides desde hace tres décadas. En los años 80 se produjo una revalorización de esta obra ovidiana, considerada hasta entonces retórica, artificiosa y repetitiva, y la crítica empezó a considerarla desde nuevos puntos de vista, más allá del análisis de las cartas como suasorias ${ }^{1}$. Las Heroides han sido estudiadas, sobre todo, como elegías en femenino, como relecturas de las versiones anteriores del mito, épicas o trágicas, realizadas por las heroínas desde sus propias perspectivas, en trabajos que plantean problemas de intertextualidad e intersección entre géneros literarios ${ }^{2}$. Otros autores ponen más el acento en su carácter epistolar, la forma que reviste la expresión elegíaca de la subjetividad amorosa (Smith 1994, Farrell 1999 y Kennedy 2002). Y en la última década han sido publicadas algunas monografías en las que podemos señalar como denominador común que las cartas se estudian como escritura de mujeres, que reescriben desde su propia perspectiva las versiones literarias anteriores de sus historias (Spentzou 2003, Lindheim 2003 y Fulkerson 2005) ${ }^{3}$. Los conceptos críticos feministas y la perspectiva de 'género' están presentes en todas ellas y en la última, la de Laurel Fulkerson (2005) se tiene en cuenta también la intratextualidad, pues analiza cómo se leen las heroínas entre ellas y forman una especie de comunidad de escritoras.

En este contexto crítico la carta de Fedra, bastante descuidada en los estudios generales sobre Heroides ${ }^{4}$, se ha estudiado como elegía en femenino con mayor o menor referencia a sus intertextos euripideos ${ }^{5}$. La mayor parte de los autores señalan tam-

\footnotetext{
${ }^{1}$ Giomini (1993) aún analiza epist.4 como una suasoria, un punto de vista presente también en el estudio general de Jacobson (1974).

${ }^{2}$ Desde esta perspectiva las estudian Kenney (1984), Barchiesi (1987), Rosati (1992), Casali (1995) y Jolivet (2000) por citar solo a algunos.

${ }^{3}$ Spentzou es la que más relevancia le da en su estudio a las cartas como escritura femenina, un aspecto privilegiado antes por Farrell (1999) al que reclama como antecedente, si bien también reconoce como tal a Anderson (1973). Ninguno de sus predecesores llegó al extremo de leer Heroides como escritura de mujeres reales, un exceso que daña un trabajo, que por otra parte no deja de tener méritos.

${ }^{4}$ No se ocupan de ella ni Jolivet (2000) ni Lindheim (2003).

${ }^{5}$ Rosati 1985 procura destacar la coherencia y autonomía de sentido del texto de Ovidio, su identidad y el código literario e ideológico que presupone, al margen de sus textos-fuente a los que se refiere muy poco. Casali 1995, en cambio, se ocupa mucho de sus relaciones con las dos tragedias de Eurípides sobre el mito de Fedra e Hipólito, lo mismo que Knox (2002) y Davis (1995) y Álvarez - Iglesias (2008).
} 
bién en la carta la presencia de intertextos de Amores de Ovidio y el carácter de mujer romana contemporánea que la heroína adquiere aquí, una mujer de tiempos de Ovidio, que en el ambiente galante del mundo elegíaco escribe una carta de seducción, que unos consideran una sustitución de la declaración oral de Fedra a Hipólito en la primera tragedia de Eurípides sobre el mito (Fulkerson 2005 y 2009) y otros la transposición elegíaca de la función que cumple la nodriza en su segundo Hippolytus (Kenney 1984; Smith 1994). Farrell (1999) y Davis (1995) piensan que la carta de seducción de Fedra es de carácter marcadamente masculino, un rasgo más de su singularidad dentro de la colección ${ }^{6}$, y no falta quien la considera un ensayo del praeceptor amoris que será después Ovidio (Landolfi 2000) ${ }^{7}$. La consideración de epist. 4 como carta de seducción no es compartida de manera unánime por la crítica ${ }^{8}$, porque, como veremos, la voz y la estrategia de Fedra no es uniforme a lo largo de todo el texto.

Partiendo de estos antecedentes y de las reflexiones teóricas que algunos latinistas han avanzado sobre el carácter de este género, que Ovidio consideraba nuevo (ars3.345-46) y que es, en efecto, un experimento a partir de otros géneros ${ }^{9}$, nos proponemos seguir el camino abierto en la década pasada y aproximarnos al estudio de la carta de Fedra desde la perspectiva de 'género': estudiaremos detenidamente la ruptura de las fronteras entre los roles masculino y femenino presente en la carta como

${ }^{6}$ Para Farrell (1999, p.318) la duplicidad de Fedra responde a una estrategia masculina, no común en la colección, puesto que las heroínas no engañan; responden a los rasgos femeninos de veracidad y espontaneidad. Davis (1995, p.44) cree que la estrategia de seducción de la carta responde a la doctrina que Ovidio imparte en Ars Amandi a los jóvenes en 1.436-486, sin mencionar los consejos que les da a las mujeres en 3.465497 sobre la escritura de cartas de amor. Rosati (1985, p.115) tampoco menciona este último pasaje.

${ }^{7}$ No faltan interpretaciones al margen de estas líneas dominantes: Torresin (1998) no cree que se pueda considerar epist. 4 una carta de seducción y hace una lectura propia con no pocas sugerencias interesantes.

${ }^{8}$ Tanto Torresin (1998, pp.206-207) como Fulkerson (2005, p.123) cuestionan esta tesis: el primero porque percibe y comenta diversos tonos de la voz de Fedra a lo largo de la carta; el segundo porque piensa que considerarla solo como carta de seducción significa ignorar muchos puntos clave del texto, particularmente aquellos en los que da detalles de su relación con Teseo.

${ }^{9}$ Farrell (1999, pp.317-329), aunque se refiere muy poco a Fedra, se esfuerza en leer las cartas como escritura de mujeres espontánea y llena de autenticidad frente a sus destinatarios que son caracterizados como mentirosos, hábiles en el manejo de la duplicidad para seducir y engañar a las heroínas a las que pérfidamente abandonan luego. Tanto este autor, como Kennedy (2002, p.220), destacan la elección de la epístola por Ovidio como muy acertada para su experimento de escritura en femenino y señalan la necesidad de estudiarlas como escritura de mujeres, porque el género ha sido considerado tradicionalmente como un género femenino por excelencia.

Ahora bien, como el autor de Heroides es Ovidio, Kennedy (2002, pp.222-228) distingue muy bien entre dos niveles de autoría y destinación: el autor Ovidio y sus lectores constituirían el nivel superior porque son ellos los que conocen la historia mitológica y literaria de las heroínas: en este nivel se produce la intertextualidad que pertenece a Ovidio, aunque se sirva de ella para elaborar las voces de las heroínas. En el nivel de autoría que le corresponde a estas se produce la comunicación con sus destinatarios, comunicación que intenta superar la distancia que las separa de ellos. Ellas escriben dentro de su historia, pero sin conocer su desenlace, e intentan determinar este de acuerdo con sus deseos; escriben como si sus historias no estuvieran cerradas ya en versiones literarias anteriores. El tiempo de su escritura es dramáticamente anterior a las versiones de los textos-fuente de los que parte Ovidio. La ignorancia de esos finales cerrados las convierte en víctimas de ironía dramática compartida por el poeta con sus lectores que también conocen las versiones completas de los mitos y de sus tratamientos literarios.

Estos dos niveles están estrechamente unidos dentro de las cartas; pero el análisis literario gana en precisión si se tienen en cuenta. 
consecuencia de la complejidad que se da en ella tanto en el plano socio-cultural como en el literario. En el primero no debemos olvidar que Fedra se encuentra en dos posiciones contradictorias; por un lado, en el juego de las relaciones de poder, ella como reina está por encima de Hipólito, un bastardo acogido en la domus de su padre sin derechos sucesorios; por otro, como mujer enamorada se encuentra en posición de inferioridad con respecto a Hipólito, de cuya respuesta positiva depende su felicidad.

En el plano literario la complejidad es aún mayor: la Fedra de epist.4 es como mujer y como escritora una creación de Ovidio, una dramatis persona, que como tal representa su papel con autonomía: le dirige un mensaje de seducción-persuasión a Hipólito, el destinatario de su carta. Pero este nivel de autoría está duplicado por otro superior, ya que quien escribe la obra es Ovidio: de él depende la transposición al código elegíaco de la voz de la Fedra trágica de los textos-fuente y la elección de la epístola como forma de comunicación verosímil para que una mujer expresara sus sentimientos y le diera rienda suelta a la subjetividad propia de la elegía. Tendríamos por tanto una doble autoría (femenina y masculina) y una destinación también duplicada: como Fedra se dirige a su lector interno (Hipólito), Ovidio lo hace a sus lectores externos entre los que nos encontramos. El poeta y sus lectores, como veremos, comparten conocimientos, con los que no cuentan ni la autora de la carta ni su lector interno, lo que convierte a la primera en víctima de ironía trágica ${ }^{10}$. Pero, además de esto, nos interesa ver cómo y hasta qué punto se introduce la voz masculina de las obras amatorias de Ovidio en la escritura femenina y cómo interactúa esta con las voces femeninas en las que el poeta también se inspira: las de los personajes femeninos de las tragedias de Eurípides y la voces elegíacas de Sulpicia, la de su propia poesía y la que pone en su boca el amicus Sulpiciae autor de 3.9 y 3.11 del Corpus Tibullianum.

La tarea que nos proponemos no es fácil, porque, aunque hemos procurado señalar los niveles en los que se mueve nuestro análisis, en el texto se encuentran a veces inextricablemente unidos. Intentaremos evitar la simplificación de aislarlos y acotarlos, cuando estas operaciones nos lleven a traicionar la ambigüedad o la riqueza significativa de un texto literario en el que además de las voces masculina y femenina interactúan los intertextos de varios géneros literarios. De modo que nos parece que la lectura lineal de la carta puede ser la mejor manera de proceder.

En la carta de Fedra Ovidio, como ya hemos avanzado, tiene como punto de partida, por un lado, la voz que le habían dado a la heroína los tragediógrafos griegos, especialmente Eurípides, y por otro, la elegíaca que le presta él mismo como poeta experimentado y experimentador en el género ${ }^{11}$. Esta es la que adopta Fedra al principio de la carta, la que la conforma como escritora elegíaca dentro de su propia historia mítica, puesto que la epístola cumple la función que cumplían las declaraciones de amor que oralmente le dirigían a Hipólito en las dos tragedias, que Eurípides le dedicó al mito, la propia Fedra en el Hippólytos kalyptomenos, la primera, y su nodriza en el

\footnotetext{
${ }^{10}$ La heroína inocentemente hace proyecciones de futuro en su carta que el autor y los lectores, conocedores del mito y sus versiones literarias canónicas, saben que no se cumplirán. De ahí el efecto irónico al que conduce la compleja intertextualidad en Heroides espléndidamente trazada por Barchiesi (1993, pp.333-335).

${ }^{11}$ En Am.2.18,19-26 Ovidio se refiere a las otras dos obras que estaba escribiendo Ars Amandi y Heroides.
} 
Hippólytos stephanías, la segunda, a las que nos referiremos a partir de ahora como Hippolytus I e Hippolytus II. Fedra en la epist.4 ocupa el mismo lugar que tenía en la tragedia; en este caso no se abre ninguna ventana dentro de la historia para añadir el punto de vista femenino ${ }^{12}$, sino que se produce una transformación en la protagonista trágica, en relación con las dos Fedras: como la segunda es incapaz de confesarle su amor a Hipólito, pero en vez de recurrir a la nodriza como intermediaria le escribe una carta; como la primera le confiesa su amor a Hipólito pero no oralmente, sino por escrito; a diferencia de ambas, a esta Fedra la epístola le permite mantener el silencio y la discreción que conlleva. Además la escribe por mandato del Amor en un momento clave de su propia historia: en ausencia de su marido Teseo se ha enamorado de su hijastro y se dispone a intentar satisfacer su deseo.

Las convenciones del género epistolar se cumplen en los primeros versos de la epístola identificada explícitamente como tal por su autora:

Qua, nisi tu dederis, caritura est ipsa, salutem

Mittit Amazonio Cressa puella uiro.

Perlege quodcumque est. Quid epistula lecta nocebit?

Te quoque in hac aliquid quod iuuet esse potest.

Le envía salud a Hipólito, una salud de la que ella, debido a su pasión, no goza ( $c f$. Hippolytus II.121-207) y de la que carecerá si el joven no lee la carta. Por eso le pide que la lea entera, temerosa ya desde el principio del rechazo de su hijastro: una carta no causa ningún daño y puede que incluso le guste algo de lo que dice. Algunos críticos han señalado aquí ironía (Jacobson 1974, p.147; Casali 1995, p.1 y Drinkwater 2007, pp.376377) puesto que en Hippolytus II Freda se suicidaba y dejaba escrita una carta para Teseo en la que acusaba a su hijastro de haber intentado forzarla. Esta falsa acusación sería la causa del trágico final joven. En efecto, para el lector externo que conoce el desenlace de la historia el efecto de estas palabras es irónico; pero Fedra, ignorante del final, no pretende ser irónica; en todo caso es ella la que es víctima de ironía dramática. La ironía se mueve en el nivel de los conocimientos compartidos entre el autor Ovidio y sus lectores, no en el de la escritora de la carta y su destinatario. ${ }^{14}$

Asimismo con la auto-presentación de Fedra como puella se nos remite a la elegía, aunque en esta era la puella el objeto de deseo del poeta, mientras que aquí es ella el sujeto, la que toma la iniciativa y la pluma. De todas formas, emplea la misma táctica victimista que el poeta elegíaco para presionar al amado proyectando sobre él la culpa de su enfermedad o de su muerte (Rosati 1985, pp.78-79) ${ }^{15}$. De hecho en lo referente a la escritura, Ovidio le presta a Fedra en líneas generales su propio perfil de poeta ele-

\footnotetext{
12 Estamos de acuerdo con Smith (1994, pp.247-248) en que las Heroides no solo abren ventanas en los textos-fuente, como sostenía Barchiesi (1987, p.66), sino que también corrigen las versiones anteriores a veces con gran éxito en la tradición.

${ }^{13}$ Citamos el texto de la edición de Moya (1986) para Alma Mater, Madrid, CSIC.

${ }^{14}$ Con acierto señala Knox $(2002,130)$ que la respuesta irónica del lector no es buscada por Fedra.

${ }^{15}$ El motivo de la enfermedad presente en la Hippolytus II.122-207 es reutilizado aquí para cumplir una función nueva en el código elegíaco.
} 
gíaco: la heroína cumple con el requisito de estar enamorada, como el poeta al final de am.1.1, tras la intervención decisiva de Cupido en el cambio de dirección de su poesía; escribe por orden de Amor (scribere iussit Amor) lo mismo que el poeta Ovidio en am.2.1.3 (hoc quoque iussit Amor); $\mathrm{y}$, si Ovidio le había ofrecido sus «manos vencidas» al dios en 1.2.20, Hipólito se las entregará a Fedra por el poder de convicción que el dictado del dios del amor le conferirá a su carta: Dabit uictas ferreus ille manus (14).

Los primeros 16 versos referidos a la escritura de la carta están cuajados de alusiones a las elegías programáticas que abren los dos primeros libros de Amores, de manera que no queden dudas sobre el carácter elegíaco de la carta de Fedra. De todas formas, su voz es la propia de una mujer preocupada por conservar el pudor y la fama, que tenía antes de enamorarse de su hijastro. Por pudor no ha sido capaz de confesarle a este oralmente su amor y escribe la carta con el fin de mantenerlo en la medida de lo posible:

Ter tecum conata loqui, ter inutilis haesit

Lingua, ter in primo destitit ore sonus.

Qua licet et sequitur pudor est miscendus amori;

Dicere quae puduit, scribere iussit Amor.

Se ha querido ver en los tres intentos fallidos de hablar una referencia a los tres esfuerzos que hacía Fedra por superar su pasión en el Hippolytus II (lucha contra el deseo, silencio sobre el mismo y suicidio ante el fracaso de los dos primeros, vv. 391-402) (Casali 1995 p.2); pero la fórmula ter ...ter ...ter se encuentra en numerosos textos poéticos griegos y latinos para describir con mayor expresividad las vacilaciones de personajes en grave conflicto anímico: desde AR 3.654 referido a Medea al propio Ovidio am.1.7.61-62. La escritura sustituye al discurso oral de Fedra o su nodriza en las dos tragedias de Eurípides, sin que esté clara aquí referencia concreta a ninguno de ellas. Lo que sí comparte esta Fedra con la de Hippolytus II es la preocupación por el pudor, que intenta mantener a pesar de su apasionado enamoramiento del joven.

Como podemos ver, estos primeros compases de la aproximación de Fedra a Hipólito son característicos de una carta de seducción, en la que para no asustar a su amado y presentarse a la mejor luz posible manipula los datos o explota apariencias engañosas: Amazonio Cressa puella uiro, como ha sido señalado muchas veces ${ }^{16}$, subraya la distancia de origen y linaje entre ambos personajes para dejar al margen de la declaración amorosa la relación familiar que los une; presentarse como puella una mujer casada y madre de dos hijos es asimismo una deformación interesada de la realidad. Y su creencia en la posibilidad de asociar el amor con el pudor (9), si no es un arma más de seducción, se debe a auto-engaño, pues solo así se podría entender esta afirmación en un contexto lleno de alusiones a $\mathrm{am}$.1.2, un poema en el que Pudor, presentado como obstáculo para Amor, aparece vencido por este en la descripción de su triunfo (32).

\footnotetext{
16 Jacobson (1974, p.147). Para Casali (1995, p.2) esta es la primera arma de seducción de la carta, aunque el sintagma tiene alusiones ocultas que reconstruyen el significado superficial: Amazonio apunta a la negación de la sexualidad de las Amazonas y Cressa al estereotipo de que las mujeres cretenses eran mentirosas. No señala este autor que la alusividad no desactiva la capacidad interna de seducción de Fedra, puesto que la alusividad se da en el nivel de la autoría correspondiente a Ovidio.
} 
Fedra está escribiendo una carta de seducción bastante ajustada en principio a la doctrina que después impartirá Ovidio en su Ars Amandi. Ahora bien, en esta obra el poeta les da buenos consejos sobre la escritura de cartas tanto a hombres (1.436-486) como a mujeres (3.465-497), y cabe que nos preguntemos qué consejos sigue Fedra. En ambos pasajes la apertura es la misma: las cartas sirven para tantear las posibilidades de éxito que puede tener un amor; pero la diferencia se establece en el segundo verso del capítulo dedicado a las mujeres, que se limitarán a responder a las cartas masculinas (accipiat missas apta ministra notas, 470), no a iniciar ellas la correspondencia. Siguen siendo iguales algunos consejos, porque al engaño permitido al joven, que promete y despierta expectativas que no está dispuesto a cumplir, corresponde el permiso que el poeta les concede a las mujeres para que contesten con la misma moneda: (iudice me fraus est concessa repellere fraudem, 491). Asimismo se les aconseja a unos y a otras el empleo de las «palabras acostumbradas» del sermo (1.467 y 3.479-80) para producir la impresión de comunicación oral directa (1.468).

Como Fedra no responde, sino que toma ella la iniciativa, podemos aceptar con Farrell 1999 y Davis 1995 que Fedra adopta, a pesar de su femenina preocupación por el pudor, una posición masculina. Ovidio da muestras en su Ars Amandi de conocer muy bien las convenciones que gobiernan la conducta masculina y la femenina: la iniciativa y el papel activo en la relación le corresponde al hombre, mientras la mujer se limitará a responder al avance. Por eso la seducción epistolar debe ser iniciada por ellos, aunque Ovidio admite que las convenciones podrían ser cambiadas: conueniat maribus ne quam nos ante rogemus, / femina iam partes uicta rogantis aget (1.27778). Si los hombres se negaran a tomar la iniciativa, tendrían que tomarla las mujeres (Volk 2010, pp.91-94).

Este es precisamente el caso de Fedra. La heroína cuando escribe la carta no sabe el desenlace trágico que va a tener su historia y por eso, como hemos dicho, para el lector culto, que como Ovidio lo conoce bien, es víctima de ironía dramática; pero Fedra sí conoce el pasado de su historia y sabe, por tanto, que no cabe esperar que Hipólito, dedicado por entero a la caza y al culto a Diana, se fije ni siquiera en ella como objeto de deseo. De modo que Fedra toma el papel activo, que, por otra parte, se explicaría muy bien por su posición superior de reina y mujer madura. En virtud de estas condiciones particulares, una carta elegíaca de seducción no resultaría inverosímil en el caso de Fedra. Por otra parte la ruptura de las barreras de 'género' por esta heroína ya tenía un antecedente literario en el Hippolytus I de Eurípides; pero en el caso de Ovidio no se produjo el escándalo que determinó en el del tragediógrafo la retirada de la obra y finalmente su pérdida. Los cambios sociales y culturales que permitieron a las mujeres romanas mayor visibilidad social e hicieron más porosas las fronteras entre lo masculino y lo femenino excluían que en Roma pudiera causar tanto escándalo una heroína transgresora.

De modo que el perfil poético de Fedra es, en principio, el de un poeta elegíaco; pero en su voz entra la preocupación por lo valores que le daban buena reputación como mujer, una preocupación que comparte con la Fedra de Hippolytus II. Por eso se propone y le promete a Hipólito mantener las apariencias: Non ego nequitia socialia foedera rumpam; / Fama, uelim quaeras, crimine nostra uacat. (17-18). 
Con su rechazo de la nequitia de los poetas elegíacos ${ }^{17}$ Fedra está afirmando su intención de no subvertir las convenciones sociales: no romperá la alianza de su matrimonio -socialia foedera - entregándose a una vida disipada. Estos versos formarían parte de su estrategia de seducción; pretenderían tranquilizar a Hipólito; pero no podía evitar la referencia a su matrimonio y de inmediato a su condición de mujer madura: Venit amor grauius, quo serior. (19). Los símiles, con los que compara el peso insoportable del amor que la hiere, subrayan paradójicamente su juventud en la peripecia amorosa: el novillo que por primera vez soporta a duras penas el yugo y el potro que se resiste al freno (21-22) así lo sugieren ${ }^{18}$. Como ellos, la heroína no tiene conocimientos previos sobre la carga que la agobia y su rude pectus desconocedor del ars amandi hace más difícil de sobrellevar su pasión. No ha sido señalado que estas dos imágenes aparecen también en am.1.2.13-16 y en ars 1.471-72, que siguen vivos como intertextos. En el primer pasaje los animales sufren menos cuanto menos se resisten, igual que los hombres que se someten gustosamente al poder de Amor; en el segundo la idea subrayada es la de que novillo y potro luchan al principio y con el tiempo se avienen mejor a su sometimiento. La comparación de Fedra está más cerca del último: ni los animales jóvenes se adaptan fácilmente al yugo y al freno, ni ella sin la experiencia del tiempo y sin ars, está preparada para soportar tal peso; pero no por eso dejan de recordar subrepticiamente que la única salida es someterse al amor, como el poeta predica am.1.2.13-16.

La negación de experiencia sigue estando al servicio de la seducción, puesto que ella aún tiene algo intacto que ofrecerle a Hipólito: su reputación. Se la presenta como noua seruatae ... libamina famae $(27)^{19}$ igual que se le ofrendan las primicias a los dioses en una actitud en la que podemos ver la encarnación del seruitium amoris de la poesía masculina que asume Fedra. Pero este equivalente de la virginidad hace tiempo perdida choca con las verdaderas circunstancias de su amor, al que ya antes se ha referido como crimen $(25)^{20}$. Las tácticas encubridoras de la seducción van perdiendo fuerza. A partir de aquí vemos mezcladas las imágenes de virginidad y candor $(29 \mathrm{ss}$.) con la confesión de que su amor los convertirá a los dos en culpables (28); su fama intacta recibirá una «insólita mancha» y solo la dignitas del amado, tan grande que no aceptaría de Juno la oferta de su marido y hermano para ponerlo por delante de Hipólito (33-36), la salvará de la vergüenza del adulterio. La heroína busca todo tipo de subterfugios para disculpar su conducta, su ruptura con el pudor y la fama, y encuentra una vía en el hecho de que su adulterio no estará agravado por cometerlo con un hombre indigno de su realeza, ya que Hipólito es también

\footnotetext{
${ }^{17}$ Ovidio la reivindica como característica de su actitud en la programática 2.1.1-2: Hoc quoque composui Paelignis natus aquosis /ille ego nequitiae Naso poeta meae.

18 Pearson (1980, pp.112-120) estudia la relación de estos símiles con el papel decisivo que tienen el toro y los caballos en el mito de Fedra e Hipólito. No advierte que Ovidio los utiliza en otros contextos para referirse con carácter general a la fuerza del amor.

${ }^{19}$ Rosati (1985, pp.116-117) y Landolfi (2000, p.21) señalan que, puesto que ya no le puede ofrecer la virginidad, le ofrece su fama intacta, como símbolo de su virginidad social, un tributo igualmente apreciable.

20 Tiene aquí el sentido de «intriga» (Palmer 1967 ad loc.). Rosati (1985, p.116) también señala que es un término casi elegíaco para designar intrigas amorosas, relaciones irregulares.
} 
hijo de reyes ${ }^{21}$ : At bene succesit, digno quod adurimur igni; / Peius adulterio turpis adulter obest. (33-34).

Esta afirmación nos remite al verso final del primer poema de Sulpicia: cum digno digna fuisse ferar (10). Fabre-Serris (2005, pp.120-130) ha estudiado detenidamente los ecos intertextuales de la obra de Sulpicia y de los poemas del amicus Sulpiciae en la carta de Fedra. Además del que acabamos de señalar, observa que el verso primero de SulPiCIA, TiB. 3.13 Tandem uenit amor subyacería al 19 de la carta ovidiana: Venit amor grauius, quo serior; y la repetición de uterque en TiB. 3.11.14-15 afloraría en Et pariter nostrum fiet uterque nocens. de epist.4.28. Esta filóloga subraya las semejanzas entre la voz de Sulpicia y la que el amicus Sulpiciae le presta, hasta el punto de atribuirle a la poetisa los poemas del amicus (Tiв.3.9 y 3.11). En nuestra opinión la intertextualidad nos lleva más bien, por medio de las semejanzas, a ver las diferencias; de manera que estos evidentes ecos intertextuales nos abren camino para examinar hasta qué punto Ovidio adopta la voz de Sulpicia o si se inclina en su experimento de elegía en femenino por seguir la senda del amicus Sulpiciae en su imitación ficticia de la voz de la poetisa.

Además de las alusiones señaladas, la carta de Fedra comparte con Sulpicia la preocupación por el pudor y la fama; pero mientras Fedra los aprecia y solo los sacrifica por amor, Sulpicia les da un tratamiento completamente diferente.

Su primer poema es un prodigio de sutileza en relación con estos conceptos ${ }^{22}$. Primero afirma de forma desafiante que prefiere que su fama no esté limitada por el pudor, que en este caso se refiere, en principio, a la acción de hablar frente al silencio que sería más recomendable: Tandem uenit amor, qualem texisse pudori / Quam nudasse alicui sit mihi fama magis. $(1-2)^{23}$.

En la conceptualización de lo femenino en Roma la fama de las mujeres dependía del pudor, entendido especialmente como reserva sexual. En estos dos primeros versos, aunque primariamente relacionado con la discreción, también está presente su significado sexual por medio de las metáforas texisse y nudasse. Sulpicia adapta ya aquí el poder subversivo de la elegía masculina a su voz elegíaca femenina ${ }^{24}$, al romper con las virtudes que la ideología patriarcal les exigía a las mujeres. Su amor es tal que paradójicamente le daría más vergüenza ocultarlo que la fama de haberlo publicado a los cuatro vientos: el pudor y la fama se convierten aquí en lo contrario de lo dictaminado socialmente. De acuerdo con esta inversión, en los dísticos siguientes se refiere al impacto social de su poesía, a los rumores maliciosos de los que se harían eco de ella los que no tienen alegrías propias que contar (5-6), para quienes sus ta-

\footnotetext{
${ }^{21}$ Me parece muy acertada la interpretación que Rosati (1985, p.117) hace de estos versos. La disculpa del adulterio por la adecuación del amante es propia de la sociedad galante y desperjuiciada de la que la elegía se nutre. El relativismo moral se impone ya aquí claramente.

${ }^{22}$ No podemos detenernos a hacer un análisis pormenorizado de la elegía, que por otra parte poco añadiría a los de Flaschenriem (1999, pp.36-45) y Milnor (2002).

${ }^{23}$ Citamos por la edición de POSTGATE (1905), Oxford.

${ }^{24}$ Wyke (1995, pp.115 y 120) señala que probablemente fue la inversión de roles sexuales de la poesía elegíaca masculina la responsable de que fuera precisamente en este género en el que se atrevió a escribir una mujer.
} 
blillas permanecerán provocadoramente sin sellar (7-8); y para terminar recoge el principio del poema en el último dístico y afirma con descaro impropio de una joven aristócrata romana: Sed pecasse iuuat, uultus componere famae /Taedet: cum digno digna fuisse ferar (9-10).

Igual que los poetas elegíacos renuncian a los valores viriles cívicos y militares por el amor, ella renuncia a los femeninos; y de hecho lo lleva al extremo de no suscribir el tópico elegíaco del seruitium amoris, que en su caso, por ser mujer, lejos de ser subversivo, la habría devuelto a las normas de la conducta tradicional femenina (Hemelrijk 1999, pp.159-169). Pero hay un movimiento contradictorio de pecasse iuuat a la dignitas final de los amantes. Dignitas pertenece al mundo de los hombres, que se merecen premios; Sulpicia la adopta para señalar la reciprocidad de sentimientos y la simetría sexual que rige su aventura amorosa ${ }^{25}$. Ha rechazado la fama y el pudor normativos en su gesto de publicar sus amores; pero hay una línea que no debe traspasar, que es la de entregarse a un amante indigno. Eso es lo que les preocupa a sus familiares en 3.16.56 y ese es el límite que ella le pone a su ruptura con la fama y el pudor. El mismo límite que tiene Fedra; pero sin que la heroína ovidiana adopte el gesto de provocación y reto a la construcción de 'género' vigente en la sociedad romana. Fedra lamenta renunciar a la fama y al pudor, por lo menos en estos primeros compases de su carta y, si bien rechaza la nequitia de los poetas elegíacos, acepta en principio, como vamos a ver, el seruitium amoris, de manera que su actitud está más de cerca de los valores propios de su 'género' que la de Sulpicia.

En el último poema de Sulpicia (3.18) volvemos a encontrarnos la misma respuesta a los 'valores femeninos', pero ahora sin el tono desafiante del primer poema, sino afirmando su arrepentimiento por haberlos respetado momentáneamente:

Ne tibi sim, mea lux, aeque iam feruida cura

Ac uideor paucos ante fuisse dies,

Si quicquam tota conmisi stulta iuuenta,

Cuius me fatear paenituisse magis,

Hesterna quam te solum quod nocte reliqui, Ardorem cupiens dissimulare meum.

Se arrepiente de haber dejado solo a Cerinto por disimular su ardor. Se esperaría que se arrepintiera de haberse entregado al amado; pero paradójicamente afirma lo contrario: la causa de su pesar es haberse marchado de su lado cediendo así a la norma convencional de que las mujeres deben disimular u ocultar su deseo (Cortés Tovar 2005, pp.217-218).

Más se parece la voz de Fedra a la que el amicus Sulpiciae le presta a esta en las elegías 3.9 y 3.11. No encontramos en ella desafíos ni cuestionamientos de los valores establecidos tan radicales como los que hemos visto en Sulpicia. Para empezar an-

\footnotetext{
${ }^{25}$ Keith (1998, pp. 295-310), que en su comentario de SULPICIA TIB. 3.17 observa semejanzas entre la pietas de la poetisa y la de Catulo en 76.2 y 76.26, nos sugiere que Sulpicia, a la que se compara con frecuencia con los epigramas de Catulo, se inspira en los poemas en que este busca la simetría sexual con Lesbia para trazar la suya con Cerinto.
} 
tes de prestarle la palabra a Sulpicia, el autor la sumerge en el género masculino de la elegía, pues la presenta en 3.8 vestida con sus mejores galas y preocupada por las apariencias, convertida en objeto de la mirada de deseo masculina, concretamente de la del dios Marte que deja sus armas para entregarse a la militia amoris de su amor. Asimismo haciéndose eco de su poesía la considera la más digna de las puellae; pero su dignitas está ahora en los aspectos externos de su doble condición de culta (1): en la púrpura y las joyas que su belleza se merece y en sus méritos para ser acogida por las Piérides en el ámbito de un ritual público, lejos del ámbito privado e íntimo representado en su poesía.

De acuerdo con esta perspectiva, cuando le presta la palabra a esta 'Sulpicia', la encontramos en 3.9 dispuesta a acompañar a Cerinto a los bosques, a pesar de haberlos maldecido (5), para servirle de ayudante (11-14) en una actitud propia del seruitium amoris. Asimismo, lejos de las palabras reales de Sulpicia en 3.13, que publicaban sus amores sin dar detalles de los mismos -ni siquiera nombra al amante-, esta quiere que se diga que ha yacido con Cerinto en el bosque en una exposición pública de su amor ajena a sus poemas. En 3.11, en cambio, aunque representa el nacimiento de Cerinto marcado por su predestinación a ser servido por las puellae y a reinar sobre ellas -te nascente noumm Parcae cecinere puellis / seruitium et dederunt regna superba tibi (3-4)-, se impone la perspectiva de Sulpicia de la reciprocidad en el amor mutuus ignis adest; mutuus adsit amor (6-7), simetría sexual que se proyecta también sobre el tópico elegíaco del seruitium amoris, que deberá ser mutuo:

Nec tu sis iniusta, Venus: uel seruiat aeque

Vinctus uterque tibi uel mea uincla leua;

Sed potius ualida teneamur uterque catena,

Nulla queat posthac quam soluisse dies.

Fedra, en cambio, se somete al seruitium amoris sin reclamarle, en principio, a Hipólito una actitud semejante. Así podemos verlo en la secuencia siguiente del poema (37-52): la Fedra ignorante del ars amandi, le comunica a Hipólito que por él se dedica a practicar ignotas... artes (37), al arte de la caza y al culto de la diosa Delia como prueba de su entrega absoluta: iudicium subsequor ipsa tuum (40). Sus acciones en el bosque -azuza a los perros contra los ciervos atrapados en las redes, lanza venablos, descansa sobre la hierba y guía los carros sometiendo a los caballos con las bridas (41-46) - constituyen su forma de entrar en el mundo de Hipólito, en el que termina perdiendo el control hasta caer en el frenesí de las bacantes (47-50).

La mayoría de los críticos ven aquí una transposición elegíaca de la escena del delirio del texto-fuente (Hippolytus II. 208-231) y señalan la diferencia de que mientras la Fedra de Eurípides solo deseaba salir al bosque a realizar estas acciones, la de Ovidio las presenta como reales -libet, iuuat, feror-. Los motivos son similares -las dos realizan las mismas acciones- y la actitud de la Fedra ovidiana, cuando recupera la razón, también mantiene algún rastro de su predecesora: me tacitam conscius urit amor (52). No siente el arrepentimiento de la euripidea, que en un gesto de recuperación del espacio recogido que le corresponde, pide que le cubran de nuevo la cabeza (244-45); pero sí siente la preocupación por lo que ha podido decir mientras estaba 
fuera de control. Esta Fedra también se preocupa por el silencio -tacitam-, por la discreción ante los otros, que han sido testigos de sus desvaríos y se lo cuentan: mihi referunt, cum furor ille remisit, /Omnia (51-52). La dimensión social de la carta de Fedra, el mantenimiento de las apariencias ante los otros, es un rasgo que aflora de vez en cuando como forma de corroborar su afirmación del v. 17: Non ego nequitia socialia rumpam. Se mantiene firme en la actitud de no hacer pública su pasión, para aminorar los daños sociales de la misma.

Aunque a los que le cuentan su furor, no les da explicaciones, sí busca una justificación del mismo ante Hipólito; y la encuentra en la venganza de Venus sobre las mujeres de su familia, porque su antepasado Helios había hecho público con su luz el adulterio de la diosa del amor con Marte: Forsitan hunc generis fato reddamus amorem/ Et Venus ex tota gente tributa petat. (53-54). Y pasa a repasar la historia de amores desgraciados sufridos por todas ellas, remontándose al rapto de Europa por Júpiter y siguiendo con el crimen de su madre Pasífae para terminar con el efecto fatal del fatum minoico sobre su hermana Ariadna y sobre ella misma (55-66).

Hasta aquí Fedra sigue defendiendo su conducta: si renuncia al pudor es porque una diosa la ha apartado del comportamiento correcto contra su voluntad. Estamos aún en la fase de seducción: necesita presentarse a una luz favorable ante el joven casto y devoto de Diana, porque Fedra, a pesar de su confianza en el mandato y apoyo de Amor en la escritura de su carta, sabe que no podrá convencer fácilmente a Hipólito para que responda a su deseo.

Estos versos (53-62) reescriben los de Eurípides, Hippolytus II 337-39; pero, mientras en la tragedia había lamento enigmático por su destino, aquí encontramos el relato de los amores antinaturales y subversivos de las mujeres cretenses como un destino de obligado cumplimiento (Jacobson 1974, p.149). Esto le permite incluir a Europa y presentarse a sí misma junto a su hermana Ariadna como dos presas cobradas por el padre y el hijo en su familia, que podrían exhibirse como trofeos en la casa del héroe ateniense (63-66 ${ }^{26}$. A diferencia de Eurípides no alude Fedra al final feliz de la historia de Ariadna: su rescate por Dioniso y su boda con él. Evita así atenuar la crueldad de Teseo (Fulkerson 2005, p.127), de manera que Fedra, además de encontrar legitimación para su conducta en el plano divino, introduce el plano humano: adelanta implícitamente la denuncia que vendrá luego del héroe como pérfido seductor de su hermana y marido insatisfactorio para ella (Davis 1995, p.55).

Al recurrir al fatum minoico para justificar su conducta ante Hipólito, pero también ante sí misma (Torresin 1998, pp.220-221) y ante la colectividad, Fedra cae en la paradoja de asimilar su amor por Hipólito a los amores antinaturales de las mujeres de su estirpe, de modo que el carácter incestuoso de la relación, presentada antes solo como adulterio, se insinúa ahora de forma más clara (Landolfi 2000, pp.22-23). Al mismo tiempo la necesidad impuesta por el destino profundiza las dudas y temo-

\footnotetext{
${ }^{26}$ Para Fulkerson (2005, p.126) el uso que Fedra hace de la evocación de su familia para explicar las circunstancias de su propia vida depende tanto de los trágicos como de la carta de Ariadna a Teseo, que en opinión de esta autora Fedra ha leído. Fedra se pone a la altura de Ariadna como víctima de un raptor: a Teseo podemos verlo así, pero representar de este modo a Hipólito es ilusorio: Theseides Theseusque duas rapuere sorores (65).
} 
res de Fedra: si a pesar del respaldo de Amor, ella dudaba del resultado de su carta - perlege quodcumque est, 3- y le rogaba al dios que la ayudara clavando sus flechas sobre Hipólito (15-16), ahora el resultado infeliz de la salida al espacio exterior de sus predecesoras se cierne como una sombra ominosa sobre ella; como en los casos de aquellas, su abandono del espacio doméstico para luchar por una vida amorosa nueva puede terminar $\mathrm{mal}^{27}$. Por eso Fedra lamenta inmediatamente después (68), al principio del relato del encuentro con Hipólito en el que se produjo el enamoramiento, haber abandonado la tierra de Gnosos.

La voz de Fedra en el relato de su encuentro con Hipólito en Eleusis y el amor que al verlo penetró en sus huesos (67-70) no depende de Eurípides. La descripción de la belleza de Hipólito (67-78) responde al código elegíaco: Fedra lo mira como miraría un poeta elegíaco a su amada, apoderándose de su físico para transmitir su deseo. Primero evoca para su destinatario la impresión de candor que le produjo su apariencia: Candida uestis erat, praecincti flore capilli, / Flaua uerecundus tinxerat ora rubor,(71-72). Luego proyecta sobre su figura la mirada de otras mujeres (aliae) que lo descalifican como rigidus y trux, y desdoblándose contrapone su visión a la de aquellas: Pro rigido Phaedra iudice fortis erat. $(74)^{28}$. Pero no lo idealiza porque su apariencia muestra el descuido que le corresponde a un joven cazador: su belleza es una belleza viril, libre de cuidados propios de mujeres, que atenúen el rigor que le da a su rostro el leuis... puluis que evoca su vida en los bosques (78). Esta belleza responde a un ideal de masculinidad que se encuentra en Cic. de off. 1.130, donde se les exige a los hombres dignidad en su apariencia, gestos y movimientos y se les recomienda un cuidado equidistante tanto de la afectación como de la grosería (Torresin 1989, pp.225-226). La forma en que presenta Fedra aquí al amado lo convierte en modelo estético, pues aparece como tal en el catálogo de los héroes apreciados por las mujeres contemporáneas de Ovidio en ars1.509-511 (Landolfi 2000, p.370).

El leuis puluis, que vela su cara, le recuerda a Fedra cómo muestra su fuerza en la caza. Frente a la facilidad con la que se mueve Hipólito, la entrega de Fedra a la caza relatada antes (37-46) es el resultado de un duro aprendizaje y se desarrolla con un gran esfuerzo (Pearson 1980, p.123). En cambio en este pasaje son los ágiles movimientos de Hipólito los que captan la mirada de Fedra, los que mantienen sus ojos fijos sobre su poderío físico, bien lo despliegue dominando a un caballo en un pequeño círculo (79-80) o lanzando dardos con su fuerte brazo; haga lo que haga Fedra no puede dejar de mirarlo: Denique nostra iuuat lumina, quidquid agis. (84). Esta mirada de Fedra ha sido considerada con razón masculina ${ }^{29}$ : su deseo físico se apodera de la ima-

\footnotetext{
${ }^{27}$ Bolton (2009, p.274-275) dice que en Ovidio la salida al espacio exterior de las mujeres es un símbolo geofísico de su persecución de una nueva identidad sexual.

${ }^{28}$ Fedra convierte rigidus en fortis (74) y mantiene la caracterización (rigor, 77) al tiempo que deja fuera trux que, como señala Landolfi (2002, pp.33-36), era propio de los hombres primitivos no dulcificados por la uoluptas y por tanto ajeno al mundo urbano y refinado de la elegía.

${ }^{29}$ Spentzou (2003, p.91), si bien acepta que la mirada de Fedra es masculina, señala una diferencia con la de los poetas elegíacos, por el arrobo con el que mira Fedra a Hipólito y porque no lo inmoviliza convirtiéndolo en puro objeto.
} 
gen del amado como la de poeta elegíaco se apodera de la de Corina en am.1.5 de Ovidio. Pues bien, desde la posición de poder que ha ocupado en estos versos pasa a persuadir a Hipólito para que ceda ante el poder de Amor.

La voz adoptada ahora por Fedra responde al modelo de la nodriza en Hippolytus II que también intentaba convencer a su señora para que dejara de luchar contra un dios tan poderoso (433-481). La relatividad moral de aquella se adapta aquí a los rasgos de carácter del destinatario, al que se pretende convertir en un joven flexible, capaz de llevar una vida más relajada y acorde con los valores de los nuevos tiempos (Rosati 1985, p.117-119): Fedra le aconseja que deje su duritia para la caza y se adapte a ella - Tu modo duritiam siluis depone iugosis. /Non sum materia digna perire tua. 85-86-. Y en los versos siguientes lo invita a alternar la dureza y la tensión de Diana con el descanso y las blanditiae de Venus, porque solo el descanso ayuda a recuperar fuerzas y a mantener la elasticidad de su arco (87-92). Recordemos que Fedra en el escenario del bosque gozaba también acostándose sobre la hierba (44). Nadie ha señalado, que sepamos, que en estos consejos de Fedra se encuentra encarnada la aspiración a la mezcla de amor con pudor, que ella se proponía seguir al principio de la carta (v.9): con la alternancia entre la devoción a la diosa de la castidad Diana y el culto al amor representado por Venus, Hipólito alcanzaría el propósito de Fedra.

Para apoyar su exhortación Fedra recurre a tres ejemplos mitológicos, que tienen en común la entrega al amor de tres cazadores: Céfalo, amado por la Aurora, que lo prefirió a su marido ya viejo; Adonis que gozó del amor de Afrodita en el escenario idílico de los bosques y Meleagro que se enamoró de Atalanta en la cacería del jabalí de Calidón. El ejemplo de Céfalo y la Aurora aparece, junto al de Zeus y Sémele, en el discurso de persuasión de la nodriza a Fedra para que acepte el dominio del amor al que no se resisten ni siquiera los dioses inmortales (451-458); pero Ovidio lo ha elegido por su condición de cazador. Junto con el ejemplo de Adonis, se adapta muy bien a la argumentación de Fedra, porque Venus como la Aurora se enamoran igual que ella de hombres jóvenes a los que tratan con la superioridad que les presta su edad y su condición de diosas (y reina en el caso de Fedra). En el de Venus, como señalan Álvarez - Iglesias (2008, p.187-188), la actitud de la diosa es casi maternal. El de Meleagro añade un matiz nuevo: el del enamorado que reconoce el mérito de Atalanta en la cacería del jabalí de Calidón y se expone a la muerte por defender su derecho a recibir la piel de la bestia.

Algunos críticos han señalado que Fedra se equivoca en la elección de los ejemplos porque en todos los casos sus historias terminaron mal, de manera que presagian el trágico final de Hipólito. En primer lugar creo que entre ellos hay diferencias que no siempre se toman en cuenta: en el caso de Céfalo el desgraciado final afecta a su esposa Procris, víctima de sus celos; en el de Adonis no está claro si el jabalí que lo mató fue enviado por Diana o por Ares (López Eire - Velasco López 2012, pp. 161163) celoso del apasionado amor que Venus sentía por el joven. De este cazador cabe recordar también que había nacido de la relación incestuosa entre Cíniras y su hija Mirra, a la que quizás aludiera Ovidio al referirse al héroe como Cinyra creatum (97). La muerte de Meleagro fue causada por su madre, que vengó así la muerte de sus her- 
manos, a los que el héroe había matado por oponerse a que el trofeo recayera en Atalanta (Ov.met.8.475-514).

Ya hemos dicho que la mayoría de los críticos consideran inadecuados estos ejemplos porque presagian el final trágico de Fedra e Hipólito. El origen de Adonis y la muerte de Meleagro, provocada por su madre, pueden recordar las semejanzas de estos mitos con la historia de Fedra e Hipólito. Pero conviene no olvidar que nada tiene que ver la relación verdaderamente incestuosa de Mirra con su padre con la que Fedra se propone entablar con Hipólito y que tampoco es ella la madre de Hipólito como Altea lo es de Meleagro. No chocan, por tanto, estos ejemplos en la escritura de Fedra, ya que selecciona a estos cazadores solo porque atenuaron la dureza de sus vidas en los bosques alternando la caza y la devoción a Diana con el amor y el culto a Venus. La ironía una vez más resulta del conocimiento compartido de Ovidio y sus lectores de los mitos completos de estos héroes; pero el discurso de Fedra tiene su propia coherencia interna. Solo en el nivel del autor de la colección, Ovidio, y los lectores externos de la carta ella aparece como víctima de ironía dramática. De todas formas es cierto que la voz del autor pesa sobre la escritura que le presta a Fedra y reclama su superioridad. El sentido que aquella le da a la lectura del lector externo se une estrechamente a la corriente de dudas que de manera más atenuada en unos casos y más explícitamente en otros expresa Fedra en su escritura

Pero sigamos con el análisis del texto. A la serie de cazadores enamorados quiere la heroína que se sume su pareja con Hipólito:

Nos quoque iam primum turba numeremur in ista;

Si Venerem tollas, rustica silua tua est.

Ipsa comes ueniam, nec me latebrosa mouebunt

Saxa neque obliquo dente timendus aper.

Aequora bina suis oppugnant fluctibus Isthmon

Et tenuis tellus audit utrumque mare.

Hic tecum Troezena colam, Pittheia regna;

Iam nunc est patria carior illa mea.

$(101-108)$

Se ha producido un cambio en el discurso de Fedra tras los ejemplos mitológicos. Ahora la heroína no habla ya de seguir a Hipólito al bosque cumpliendo con el seruitium amoris como en su primera aproximación al mundo de su amado (37-50). Esta actitud propia de la elegía no aparece en los ejemplos: Cephalus es clarus, como la Aurora (93); los prados sostienen a Adonis y Venus iguales en el amor (98) y Meleagro le cede la piel del jabalí a Atalanta porque fue la primera en herirlo. Fedra habla en plural de su pareja con Hipólito: nos quoque...(101) y se presenta como comes del joven y como fortalecida por el amor para enfrentarse a los peligros de una silua dulcificada por el amor, no ya rustica como sería si se eliminara a Venus de ella (102). La heroína ahora se imagina a sí misma viviendo una vida entre iguales con un Hipólito renovado tras su exhortación, realizando la simetría sexual que afirmaba Sulpicia en el último verso de su primera elegía. Habitará con él en las proximidades de Trezén, en el istmo próximo azotado por dos mares y, a pesar de que este paisaje de alguna manera sugiere la relación conflictiva que se propone, Fedra se imagina una 
felicidad en el reino de Piteo que lo convierten ya en una tierra más querida para ella que su patria ${ }^{30}$.

Esta primera visión de su vida futura con Hipólito es una visión idílica y alejada de la realidad social, un paréntesis en una vida, como lo habían sido los amores de los ejemplos mitológicos evocados arriba; pero Fedra pone de repente los pies en la tierra y pasa a presentar los problemas reales a los que tiene que enfrentarse como esposa de Teseo: emprende su intento de persuadir a Hipólito con otro tipo de argumentos.

Teseo hace tiempo que los tiene abandonados: lo retiene su amado Pirítoo, al que antepone en su corazón a su esposa Fedra y a su hijo Hipólito (109-110). Es la primera vez que aparece la insinuación de que entre ambos héroes había una relación erótica (Jacobson 1974, p.152). Fedra se presenta así como una heroína abandonada, igual que las demás; pero se diferencia de ellas porque no intenta recuperar a su marido, como Penélope, enviándole una carta. Busca, en cambio, otra relación y precisamente con el hijo de su marido asimismo abandonado por él. Los dos se encuentran en una relación simétrica en lo que respecta al trato que han recibido de Teseo; por eso intenta convertirlo en su cómplice recordándole los motivos que ambos tienen para vengarse de él, los daños que su crueldad causó en las familias de ambos (112-124). El adulterio de Fedra está perfectamente justificado por la ausencia de Teseo (Rosati 1985, p.119; Torresin 1998, p.228; Landolfi 2000, p.38), y la respuesta de esta no hace sino reproducir la conducta de su marido estableciendo simetría sexual entre ellos. El mismo Ovidio niega que la conducta de Helena pueda considerarse adúltera, puesto que la favoreció su marido con una ausencia excesiva: nil Helene peccat, nihil hic committit adulter: / quod tu, quod faceret quilibet, ille facit. (ars 2.365-366). Pero además se trata de un acto de venganza en la que los dos amantes, Fedra e Hipólito, encontrarían satisfacción.

La voz de Fedra en este pasaje puede estar inspirada en Hippolitus I, tragedia en la que Fedra formulaba acusaciones contra Teseo como justificación de su amor por Hipólito (PLuT.de audiendis poetis 8,2899). En Hippolitus II nos encontramos, en cambio, con una Fedra virtuosa, una inversión de la primera especialmente en lo que se refiere al respeto y afecto que manifiesta por Teseo y sus hijos. Precisamente una de las razones que más la empujan a conservar el 'aidós' y la buena reputación es que de ellos dependen el honor de sus hijos, su pudor les asegura la 'parrhesía' en la polis ateniense (420-425). El parlamento de Fedra en Hippolitus II es el de una mujer preocupada por cumplir con sus deberes de reina, evitando que su conducta sexual pueda poner en peligro las funciones cívicas de los hombres de su familia ${ }^{31}$. Es posi-

\footnotetext{
${ }^{30}$ Aquí se encuentra la primera proyección de una vida futura juntos en Trezén, a la que seguirá la que pueden vivir en la casa de Teseo en Atenas (129-148) y como última alternativa una vida de reyes en Creta (163-164). Sobre estas tres vidas soñadas y propuestas por Fedra a lo largo de su carta, v. Torresin 1998, pp. 212-235.

${ }^{31}$ Fiorensis - Gianotti 1990, pp. 72-73, señalan que en el trasfondo de todas las tragedias griegas sobre el mito de Fedra e Hipólito estaría la Fedra «política», que había entrado en el complejo del mito de Teseo para sancionar alianzas con los sucesores de Minos y poner finalmente un poco de orden en las caóticas relaciones del héroe ático con sus innumerables mujeres.
} 
ble que el escándalo provocado por el descaro de la Fedra de Hippolitus I se debiera a su desprecio manifiesto por tales deberes (Álvarez - Iglesias 2008, pp.189-190).

Pues bien, no sabemos hasta qué punto la Fedra de Ovidio recupera la voz de la de Hippolitus I; pero sí es seguro que lleva al extremo su rechazo de la ideología representada por la de Hippolitus II. En su carta a Hipólito Fedra pone por delante de sus hijos a su amado, cuando lamenta que su padre lo privara del derecho a heredar su reino al no legitimarlo casándose con su madre la amazona, y llega a maldecir sus partos que lo privan definitivamente de toda esperanza sucesoria (120-126). Si en Hipólito II la nodriza recurría, contra la intención de Fedra de quitarse la vida, al argumento de que sus hijos la necesitaban viva para asegurarse la sucesión en el reino de Teseo ante las posibles pretensiones de Hipólito (305-308), aquí ella opta por este y lamenta haber parido a los hijos legitimados por Teseo, que le han quitado a su amado la posibilidad de heredar el reino (123-126). Esta es la mayor injusticia cometida contra su joven hijastro y la que la lleva a invitarlo sarcásticamente a rendirle al lecho de su padre la reverencia que se merece: I nunc, et meriti lectum reuerere parentis, / Quem fugit et factis abdicat ille suis. (127-128). Cierra así este capítulo recogiendo la referencia al abandono, tema con el que lo abría en 109-110. Su insistencia en el abandono que sufre la aproxima a las demás heroidas; y el hecho de presentar su adulterio como venganza por la infidelidad de Teseo nos recuerda a su madre Pasífae que también castigó el adulterio de su marido Minos engañándolo con el toro (Fulkerson 2005, pp.127-135).

De todas formas, ante la posibilidad de que el piadoso Hipólito se resista a su amor alegando el obstáculo más grave del incesto, Fedra recurre al argumento de que el matrimonio de Júpiter con su hermana ha desplazado definitivamente la uetus pietas de los rústicos tiempos del reinado de Saturno (129-136). La defensa de la relatividad moral en relación con el amor estaba en Hippolytus II en boca de la nodriza (462469), pero aquí sigue derroteros propios $^{32}$. Fedra defiende en este pasaje, que Rosati considera el corazón teórico de la epístola (1985, pp.119-120), una nueva moral más flexible y adaptada a los tiempos, que conlleva la defensa de la licitud del incesto. La edad de Saturno era un paradigma de moralidad en la propaganda augústea, en la que se encarnaba la integridad de las viejas costumbres, los ideales de la castidad y el respeto a los lazos familiares propios de la sólida moral de los campesinos virgilianos (VIRG. Georg. 2.450-548-365 y Aen. 8,319-65): Fedra desmitifica ese pasado con fines eróticos y se apoya en la ruptura de Júpiter con él, ruptura que presenta como un avance liberador hacia una ética sexual más flexible, de la que pretende hacer partícipe a Hipólito (Landolfi 2000, pp.38-39). Y de acuerdo con esta nueva moral Fedra pasa a cumplir el papel de la nodriza, pero con los rasgos, en opinión de muchos críticos de una lena elegíaca ( Kenney 1982, pp.423-24; Rosati 1985, pp.125-128; Casali 1995,

\footnotetext{
${ }^{32}$ No es verdad que estos versos no le deban nada a Eurípides, como pretende Jacobson (1974, p. 152). Los argumentos de Fedra son diferentes a los de la nodriza porque son romanos y contemporáneos, pero parten en términos generales del texto-fuente, puesto que la función persuasiva, que allí cumplía la nodriza, la cumple aquí Fedra con Hipólito. En lo que sí hay una gran diferencia es que en la carta Fedra habla claramente de incesto, mientras en Eurípides Hippolytus II ni la nodriza ni el propio Hipólito lo mencionan: el protagonista habla de profanación del lecho paterno, no de incesto (651-668).
} 
p.6; Álvarez - Iglesias 2008, p.179). Fedra descaradamente saca consecuencias positivas del parentesco que los une: la cohabitación favorece el mantenimiento de sus amores en secreto (Nec labor est celare; licet... (137) y facilita la ocultación de la culpa $(138,145)$, permite incluso la manifestación pública de afectos que los otros atribuirán al cariño entre familiares y, lo que es más importante en el código elegíaco, Hipólito no tendrá que temer a un marido rígido ni a ningún custos (137-146). Los resultados en los que desemboca su persuasión son curiosamente anelegíacos, puesto que desaparece la ansiedad de superar los obstáculos ${ }^{33}$. No ha sido señalado que aquí Fedra, como en el pasaje anterior invierte una vez más la voz de la Fedra euripidea de Hippolytus II. Esta manifestaba su desprecio hacia las mujeres que se atrevían a engañar a escondidas a sus maridos y no solo por motivos morales puesto que insiste mucho en el temor de ser descubierta en acción deshonrosa (412-420). La Fedra ovidiana, inmersa en el código galante no tiene escrúpulos morales ni preocupación por las consecuencias sobre su marido e hijos, que no le importan. Su propuesta de ocultación puede ser en primer lugar una concesión a la reticencia de Hipólito, al que aún sitúa entre los que verían su furtiuus amor como una gran culpa ${ }^{34}$, pero también es concesión a la discreción social que le ha puesto desde el principio límites a su carácter transgresor. Recordemos que al principio de la carta prefería a la nequitia de la elegía masculina el respeto de los socialia foedera de su matrimonio con Teseo (17) y que consideraba 'digno' su adulterio con Hipólito (33-34). En este contexto es inevitable relacionar el pacto que ahora le propone a su hijastro, no solo con el foedus propio de la elegía masculina ( $c f$. PROP. 3.20.15-18), sino también como señal de dignificación de sus amores, que, de todas formas, por mantenerse ocultos seguirán respetando los límites sociales.

A continuación, insegura de que sus argumentos puedan doblegar el carácter de Hipólito, cambia de registro y le ruega compasión:

Non ego dedignor supplex humilisque precari.

Heu! ubi nunc fastus altaque uerba? Iacent.

Et pugnare diu nec me submittere culpae

Certa fui, certi siquid haberet amor

Victa precor genibusque tuis regalia tendo

Bracchia. Quid deceat, non uidet ullus amans.

Depuduit, profugusque pudor sua signa reliquit.

Da ueniam fassae duraque corda doma.

En estos versos (149-156) pasamos del tono racional de su discurso a la manifestación de su debilidad y emotividad. Ella pierde su dignidad de reina y tiende sus manos suplicantes a las rodillas de su amado (149-156). Aquí por primera vez se re-

\footnotetext{
33 Así lo señala Landolfi (2000, p.40), que comenta el pasaje en clave de lección de amor, con la actuación de Fedra como praeceptor amoris, una función en la que de todas formas se diferencia mucho del maestro del Ars Amandi, ya que ella no le da a sus lecciones el alcance universal que tienen las de Ovidio, sino que las ajusta a su situación específica.

${ }^{34}$ Defendida la licitud del incesto, Fedra no consideraría culpable su amor; pero sabe que su opinión no necesariamente era compartida por la sociedad romana y especialmente por Hipólito. Además ella, como vamos a ver, también ha tenido que hacer un gran esfuerzo para superar la mala conciencia que sentía por su deseo.
} 
fiere a la lucha sostenida contra su deseo antes de que Amor la decidiera a escribir la carta: Et pugnare diu nec me submittere culpa / Certa fui, certi siquid haberet amor (151-152). Hemos visto el camino recorrido por Fedra en sus intentos de seducción y persuasión de Hipólito; la hemos contemplado en la posición de poder que le daban el dictado de Amor y su condición de reina; la hemos visto dudar porque, conocedora de Hipólito, no se sentía segura de convencerlo y conquistarlo; ahora la encontramos en su momento más bajo: abatida e impotente, a pesar de su propia voz previa destinada a convencer a Hipólito y a autoconvencerse de la justicia de sus pretensiones, recurre a la súplica. Su discurso anterior se viene abajo como un castillo de naipes (ubi nunc fastus altaque uerba? Iacent. 150); ahora es ella, uicta, la que tiende las manos a Hipólito y no es él quien, vencido, se las tiende a ella, como Amor le prometía al principio (14). Es consciente de la falta de decorum de su comportamiento, inadecuado para una reina, pero (Quid deceat, non uidet ullus amans, 154) ha perdido la vergüenza, la ha abandonado el pudor. Pero pudor ¿en qué sentido? Quizás tanto en el de 'vergüenza' como en el de 'recato'; pero las metáforas bélicas nos inclinan más a atribuirle el último, puesto que profugus y sua signa apuntan a que Amor lo ha vencido y a lo largo de la carta y especialmente a estas alturas de la misma ya no se sostiene el esfuerzo de su combinación con el amor. Fedra siente que quizás ha ido demasiado lejos en sus intentos anteriores de persuasión (109-147). La súplica suena a arrepentimiento, puesto que le pide perdón a Hipólito por su confesión ( $\mathrm{da}$ ueniam fassae, 156); pero las vacilaciones de la heroína son tan grandes en este final de la carta que también sería posible ver aquí un intento de recuperación de su voz primera, la de la seducción: quizás la adopción de una imagen de mujer indefensa más acorde con los requerimientos de su 'género', (y con la ideología que tenía que suponerle a Hipólito) y más inclinada al seruitium amoris, es una de sus últimas armas para doblegar al joven.

De todas formas no se olvida de su linaje y le pide a sus hijastro que responda a sus súplicas en consideración a sus antepasados (Minos, Júpiter y Helios 157-162): su nobilitas sub amore iacet (161). Si la rechaza, la reputación de los suyos se verá dañada. La dimensión social se introduce de nuevo en la carta: no importa lo que pueda sentir Hipólito por ella ni que la razón de su asentimiento no responda al amor, sino a las ventajas que su posición social pudiera ofrecerle. Por eso le propone una última alternativa para su vida juntos: Est mihi dotalis tellus Iouis insula, /Crete; / Seruiat Hippolyto regia tota meo. (163-164). Le ofrece un reino que es solo suyo, en el que podrán vivir sin conflictos, lejos de los reinos de Piteo y de Teseo donde situaba antes su vida futura juntos y donde había surgido su pasión culpable. Y sigue intentando doblegarlo con sus súplicas: Flecte, ferox, animos. Potuit corrumpere taurum / Mater; eris tauro saeuior ipse truci? (165-166). En su falta de esperanza Fedra se muestra más realista en la visión de Hipólito: ya no son otras puellae las que lo ven trucem (73), es ella misma la que lo llama ferox y lo compara con el toro de Pasífae (tauro...truci, 166). ¿Podían servir de apoyo a sus súplicas estas evocaciones? Ciertamente la evocación de sus antepasados cretenses y de la aventura de su madre con el toro no eran muy adecuadas para doblegar a un joven casto y misógino, como por fin reconoce Fedra en 173-174: quamuis odisse puellas / Diceris.... De todas formas no le 
desea a Hipólito la suerte que ella está sufriendo (Sic numquam, quae te spernere possit, ames; 168), sino que siga con su vida protegido por Diana y los dioses y ninfas que habitan los bosques (169-174) Y termina invitando a Hipólito a imaginarse las lágrimas que acompañan sus súplicas: Addimus his precibus lacrimas quoque. Verba precantis / Perlegis; et lacrimas finge uidere meas. (175-176). Quiere que Hipólito no solo lea, sino que también se la imagine llorando mientras suplica. Esta es la forma en que la epístola intenta superar la ausencia y traer a su destinatario a presenciar la imagen patética de la escritora. También Dido le pide a Eneas en epist. 7.183-186 que se la imagine escribiendo con su espada en el regazo regándola con lágrimas, la espada que se emparará en breve con su sangre.

En estos versos finales de la carta también ha visto la crítica presagios del final trágico de Hipólito, en la evocación de los antepasados de Fedra y sus relaciones con los toros (Júpiter y Europa, Pasífae), especialmente en la comparación de Hipólito con un toro salvaje y cruel; y ha señalado la ironía que resulta de ella, puesto que un toro (y los caballos, muy presentes también en la carta) sería el responsable del final trágico del joven (Jacobson 1974, p.152). Una vez más tenemos que decir que el efecto irónico se produce en el nivel superior de autoría y lectura; pero también debo añadir que la elección de Ovidio de esta materia para el final patético de Fedra, para su heroína, que se ha desmoronado y que no cree ya en los sucesivas ensoñaciones anteriores de una vida futura con Hipólito, es muy eficaz, porque proyecta sobre ella ese futuro trágico que Fedra no ha contemplado a lo largo de la carta y al que en su desesperación final no se refiere como posibilidad, pero al que, en el estado psíquico en que llega, estaría sin duda abocada. El paralelismo con su madre es la clave interna de esta atmósfera pretrágica de los últimos versos de la carta.

Con esto damos por terminado el análisis y vamos a sacar algunas conclusiones. La carta de Fedra no responde al modelo más común en la colección de heroína traicionada por un héroe y abandonada por él, que aspira a recuperarlo y a establecer una relación estable con su amado, como una uxor legítima. Fedra es una heroína transgresora, que cruza las fronteras de 'género' o fuerza los límites como lo había sido la primera Fedra literaria de Eurípides; pero que desde el principio le pone algunos límites a su transgresión porque, a pesar de ocupar la posición del poeta elegíaco, intenta dejar a salvo el pudor, al menos en su dimensión social.

Vemos evolucionar a lo largo de la carta las voces de Fedra: ocupa la posición del poeta elegíaco, pero renuncia a su nequitia y así mantiene un ancla en su cumplimiento de los requerimientos de su 'género' y estatus social; de acuerdo con esto no subvierte abiertamente, como lo hizo Sulpicia, los valores femeninos del pudor y la fama. Intenta un difícil equilibrio entre ellos y el amor prohibido que se propone alcanzar. No llega a escribir una elegía en femenino, porque no rompe con el seruitium amoris, que a ella, frente a los poetas elegíacos, la sitúa en la posición tradicional de inferioridad: pero evoluciona a lo largo de la carta y toma de Sulpicia (y de su amicus) la aspiración a la simetría sexual que rompe las fronteras convencionales de 'género'. Así lo hemos visto en la segunda escena de caza, situada en un mundo bucólico, ideal y mítico de Trezén y también en la reclamación, más racional y cuidadosamente argumentada, de una infidelidad simétrica a la de su marido, basada en su derecho a 
vengarse de las crueldades de Teseo. A sus justas razones, le suma para el convencimiento de Hipólito la defensa de una moral relativa y adaptada a los tiempos que no excluiría la legitimación del incesto; pero le pone un límite basado de nuevo en consideraciones sociales y promueve un amor furtivo con Hipólito basado en la ventaja que les da compartir la misma casa. Todos los esfuerzos invertidos en ignorar el carácter de Hipólito se vienen abajo al final, Fedra se desmorona y cambia su voz a la súplica. Con esto termina su actitud transgresora y su sometimiento dolorido a la realidad de su desesperanza: ha perdido el pudor y el amor la somete como al resto de las heroínas.

Esta carta ha sido leída como una desacralización de la uxor y un pulso de Ovidio a la ideología augústea (Arena 1995, pp.832-834). Ciertamente la carta de Fedra evoca los valores que una uxor y una reina debía atesorar, de manera que representa de un modo más claro sus transgresiones; pero, como hemos visto, Ovidio, no deja de ponerle límites a estas rupturas sociales y literarias. Fedra no llega a ser una escritora de elegía en femenino: su voz está traspasada de ecos de los géneros masculinos y le debe mucho a sus convenciones. Si leemos la carta en el conjunto de la colección, llegamos a la conclusión de que, en efecto, rompe más con la ideología patriarcal que las demás; pero las Heroides no son, como las describen Rosati (1992) y Lively (2005), la realización de un tipo elegía sin tensiones, porque sus aspiraciones de fidelidad y estabilidad emocional encajan mejor con la situación de inferioridad de las mujeres, que con las de los poetas-amantes elegíacos. Más bien estamos de acuerdo con Davis (2005, p.68), cuando señala que las heroínas son fieles pero reclaman reciprocidad de sus amados; y en esto hemos visto que Fedra no se queda atrás. Las $\mathrm{He}$ roides son el producto de una edad en la que la sociedad romana ya no tenía nada que ver con Grecia ni con los valores morales de la vieja República, una sociedad en la que la cultura y las riquezas han liberado a las mujeres de clase alta, aunque siga siendo una sociedad patriarcal y, sobre todo, en la que la poesía, especialmente la elegía, ha desestabilizado en gran media los estereotipos de género y ha propiciado un pequeño nicho de poesía femenina que se podía convertir en un modelo y que lo fue para un poeta como Ovidio que apreciaba mucho la poesía de mujeres. Y todo esto a pesar del riguroso control con el que el sistema excluyó sistemáticamente a la mujeres de la producción literaria (Habinek 1998, pp.122-136); de manera que, si tuviéramos que responder a la pregunta del título del artículo de Fulkerson, «The Heroides: Female Elegy?» (2009) lo haríamos con matices y diríamos que si no son elegías en femenino al menos plantean muchos problemas sobre escritura de mujeres y sus diferencias con respecto a la escritura de sus contemporáneos poetas.

\section{REFERENCIAS BIBLIOGRÁFICAS}

Álvarez, C. - Iglesias, R. (2008), «La Fedra de Ovidio», en PociñA, A. \& LóPez, A. (eds.), Fedras de ayer y de hoy. Teatro, poesía y cine ante un mito clásico, Granada, Editorial Universidad de Granada, pp. 171-193.

Bolton, M. C. (2009), «Gendered Spaces in Ovid’s Heroides», CW 102, 273-290. 
Anderson, W.S. (1973), «The Heroides», en Binns, J. W. (ed.), Londres - Boston, Routledge - Kegan Paul, pp. 50-67

BARCHIESI, A. (1987), «Narratività e convenzione nelle Heroides», MD 19, 61-90.

BARCHIESI, A. (1993), «Future reflexive: Two modes of Allusion and Ovid's Heroides», HSCPh 95, 333-365.

Casali, S. (1995), «Strategies of Tension (Ovid, Heroides 4), PCPS 41, 1-15.

Cortés Tovar, R. (2005), «Poesía de mujeres en Grecia y Roma», en SEvillano, C., RodríGuEz, J., Olarte, M. y Lahoz, L. (eds.), El conocimiento del pasado. Una herramienta para la igualdad. Salamanca, Plaza Universitaria Ediciones, pp. 201-218.

Davis, P. J. (1995), «Rewriting Euripides: Ovid, Heroides 4», Scholia, 4, 41-55.

Davis, P. J. (2006), Ovid and Augustus. A political reading of Ovid's erotics poems, Londres, Duckworth.

Drinkwater, M. O. (2007), «Which letter? Text and subtext in Ovid's Heroides», AJPh 128, 367-387.

FABre-Serris, J. (2005), «Sulpicia: une autre voix feminine dans Les Héroïdes. Propositions de lecture des lettres 4 et 15», REL 83, 120-135.

FARrell, J. (1998), «Reading and Writing the Heroides», HSCPh, 98, 307-338.

Fiorencis, G. - GianotTI, G.-F. (1990), «Fedra e ippolito in provincia», $M D$, 25, 71-114

Flaschenriem, B. L. (1999), «Sulpicia and the Rhetoric of Disclosure», CPh 94, 36-54.

Fulkerson, L. (2005), The Ovidian Heroine as Author. Reading, Writing and Community in the Heroides, Cambridge, Cambridge University Press.

Fulkerson, L. (2009), «The Heroides: Female elegy?», en Knox, P. E. (ed.), A Companion to Ovid, Oxford, Willey-Blakwell, pp. 78-89.

Giomini, R. (1993), «Ancora sulla struttura retorica nelle Heroides ovidiane: l'epistola di Fedra a Ippolito», en Amata, B. (ed.), Cultura e lingue classiche 3, Roma, pp. 347-358.

HABINEK, T. N. (1998), The Politics of Latin Literature: Writing, Identity, and Empire in Ancient Rome, Princeton, N. J. Princeton University Press.

HemelrijK, E. (1999), Matrona Docta: Educated Women in the Roman Élite from Cornelia to Julia Domna, London, Routledge.

Jacobson, H. (1974), Ovid's Heroides, Princeton, N. J. Princeton University Press.

Jolivet, J. C. (2001), Allusion et fiction épistolaire dans les Héroïdes: Recherches sur l'intertextualité ovidienne, Paris, Collection de l'École Française de Rome, 289.

KeIth, A. (1998), «Tandem venit amor: a Roman Women speak of love», en Hallett, J. Skinner, M., Roman Sexualities, Princeton, N. J. Princeton University Press, pp. 295-310.

Kenney, E. J. (1982), «Ovid», en Kenney, E. J. - Clausen, W.V. The Cambridge History of Classical Literature II: Latin Literature, Cambridge, Cambridge University Press, 420457.

Kennedy, D. (2002), «Epistolarity: The Heroides», en Hardie, Ph.(ed.), The Cambridge Companion to Ovid, Cambrige, Cambridge University Press, pp. 217-231.

Knox, P. E. (2002), «The Heroides: elegiac voices», en WeIDEN-Boyd, B. (ed.), Brill's Companion to Ovid, Leiden, Brill, pp. 117-139.

LANDolfi, L. (2000), Scribentis imago. Eroine ovidiane e lamento epistolare, Bolonia, Patrón Editore

LindheIm, S. H. (2003), Mail and Female. Epistolary Narrative and Desire in Ovid's «Heroides», Madison, The University of Wisconsin Press. 
Liveley, G. (2005), Ovid: Love Songs, Bristol, Bristol Classical Press.

LÓPEZ EiRE, A. - VelASCO LÓPEZ, H. (2012), La mitología griega: lenguaje de dioses y hombres, Madrid, Arco/Libros S.L.

MiLnor, K. (2002), «Sulpicia’s (Corpo)reality: Elegy, Authoship, and The Body in [Tibullus] 3.13», CAnt, 21, 259-282.

Moya, F. (1986). Ovidio. Heroidas, Texto revisado y traducido, Madrid, CSIC.

PeArson, C.S. (1980), «Simile and imagery in Ovid' Heroides 4 and 5», ICS 5, 110-139.

Posgate, J. (1905), Tibulli aliorumque carminum libri tres, Oxford, Oxford University Press.

Rosati, G. (1985), «Forma elegiaca di un simbolo letterario: la Fedra di Ovidio», en UGLIONE, R. (ed.), Atti delle Giornate di Studio su Fedra, Turín, CELID, pp. 113-131.

Rosati, G. (1992), «L'elegia al femminile: le Heroides di Ovidio (e altre heroides)», MD 29, 71-94.

Smith, R. A. (1994), «Fantasy, mith, and Love Letters: text and tale in Ovid's Heroides», Arethusa 27, 247-273.

Spentzou, E. (2003), Readers and Writers in Ovid's Heroides. Transgressions of Genre and Gender, Oxford, Oxford University Press

Torresin, G. (1998), «Ovids Phaedra in der mythologischen Tradition Ep. Her. 4 - der Brief einer Person Delirans», $C \& M$ 49, 163-235.

Volk, K. (2010), Ovid, Oxford, Wiley-Blacwell. 